\title{
EMERGENT INDIGENOUS IDENTITIES: REJECTING THE NEED
}

\section{FOR PURITY}

\section{Michelle Harris}

In November 2009, a colleague sent me a CNN.com story about 'New Jews'-those who were exploring ways of accessing, understanding, and performing their identities as contemporary Jews. "It's true, for the first time in thousands of years that we can build the identities we want," one interviewee said, as the author highlighted ways that younger believers expressed their Jewish-ness, including tattooing Stars of David on their chests and performing punk-rock renditions of Jewish prayers (Ravitz 2009).

The article illustrated something which had recently captured my imagination, but the articulation of which eluded me: that contemporary indigenous identities can be "new" even as they are rooted in the ancient-a paradox if ever there was one. It forced me to delve deeper into my thinking about a term I had been using'emergent'-and I began to see it as a space indigenous peoples carve out to be who they are. It is a complex space informed by historical moments, place, social forces, and the everyday of their lives. Of course, to claim Indigeneity is to self-consciously recognise that certain cultural "traits" (such as language, religion, ancestry) are important emblems in representing one's self, and in mobilising these emblems as signifiers of belonging, one is, in part, making a political statement of solidarity with others who also identify as indigenous (DeVoss 1995; Levi \& Dean 2003).

Both those who claim indigenous identity and outsiders often seem to fall into a trap of paradoxes-acknowledging complexity on the one 
hand, while reifying notions of 'tradition' and 'authentic cultural expression' as the core features of an authentic indigenous identity on the other. Of course, to claim difference is to eschew simplicity, or at least, straightforwardness - a condition that seems suited to being able to name and define that which constitutes the authentic. Authenticity also connotes a hegemonic state-one that is over-arching and predominant. Yet, scholars of indigenous identity challenge the notion of a hegemonic indigeneity, especially when the claimants range from those who were born to and are historically rooted (socially and culturally) in the practice of their identity, those who come to a knowledge of this identity status later in their lives, and those who may have been cut off from cultural or social institutions that offer opportunities and constraints that define and outline the parameters of how to 'be' indigenous. If one cannot 'be' in the right way, does one get to 'be'?

In this chapter, I want to rearticulate contemporary indigenous identity (primarily as it relates to those people in the latter group who face the challenge of accessing and claiming "authentic" indigenous identities) as an emergent phenomenon and in a way that is free of cultural essentialisation. I want to highlight agency, or the 'emergent' in identity formation and to recognise how positionality-or where we are in the social order-further complicates how identities are enacted. Additionally, I will borrow from writings about the concept of the 'Creole' or 'Creolisation,' not to claim that Indigeneity is a form of the being Creole, but rather to illuminate how contemporary forms of being indigenous highlights cultural accretion or mixing.

\section{Moving Beyond the "Real" Indigene}

Two presuppositions frame identity politics around indigenous identity (Taylor 1994). The first has to do with the ideal of the 'pure', 
'authentic', or 'real'. Clearly articulated, the assumption is that a binary exists: one either displays an 'authentic' indigenous identity (which is essentially primordial and displayed in culturally appropriate ways), or one does not. The second presupposition is that if identity is real, then others will know it. In other words, it will be distinguishable, and if it is either unrecognisable or misrecognised, then it cannot be true. Therefore, those who perform Indigeneity are open to censure, rejection and exclusion from their communitiesespecially if they deviate from or misrepresent what is thought to be the 'right' or 'real' way to do things. Of course, much of this realness is tied up in beliefs of tradition and authenticity. As Conklin (1997) points out, there is a great deal of symbolic capital that ensues from authentic performance, especially in the absence of group access to important economic and political resources. Who establishes the boundaries within which one must perform? Forces both from within and outside of indigenous communities seek to construct, define, name, and police indigenous identities, and in doing so, a constant battle ensues in the shifting sands on which the play for authenticity is performed (Ariss 1988; Bourdieu 1990; Ang 2001).

Paradies (2006) eloquently speaks to some of the pitfalls inherent in defining and regulating the identity formation and performance of Aboriginality in Australia. Others have echoed similar sentiments in relation to minority and indigenous peoples in other sites around the world. ${ }^{1}$ Ideas about the primordial nature of indigenous culture and ethnicity not only delimits its possession to those who can claim uninterrupted access to indigenous culture and identity through ancestry, but also creates a situation where many people may fall into a trap of idealising a mythologised and fetishised authenticity that is

\footnotetext{
${ }^{1}$ For examples see Gilroy 1993; Sylvian 2003; Anthias, 2001; Bruner and Kirshenblatt-Gimblett 2004; and Fiske 2006
} 
rooted in a tradition that has most likely been impacted by centuries of colonisation, conquest and/or outsider influence. I do not suggest that indigenous culture should not be named as such, that it does not exist, or that attempts to define, perform or celebrate such a cultural identity ought to be abandoned. Rather, I question the existence of a pure, singular, hegemonic form that unifies all individuals who claim indigeneity. Moreover, I contend that identity, rather than being expressive of a definable cultural tradition, is formative: it emerges from particular historical moments, experiences, relations, position with the social order, and from both the opportunities and constraints that govern our realities. This means identities are formative and constitutive, not merely reflexive (Hall 1989).

One of the most crippling problematics of the stricture of a pure cultural form is the assumption that 'culture' is ontological-and to the extent that it exists, it must do so in some true, identifiable dimension. This is illustrated in the very popular conception that indigenous peoples have a mystical and ancient, or as Goldie (1989) termed it, "prehistoric" tie to that which was (culture, land, behaviors), so as to make their existence today irrelevant. This irrelevance exists if one can make claim to accessing 'pure' forms of culture (which then has no true relevance in today's world), or if one claims Indigeneity but has no claim to land, 'pure' cultural traditions, or has recently claimed indigenous identity (no claims to ancient signifiers means your claim is irrelevant because you are not really part of the culture).

An indigene of today cannot then be the same as an indigene of fifty years ago, much less one who lived one thousand and fifty years ago. It also means one pure or hegemonic racial/ethnic/cultural identity is unlikely, though many in the same ethnic group may, for example, experience some similar events and realities at a particular moment. The diversity of subjective positions will result in a contested, 
contextual, situated, and nuanced sense of what it means to belong to a particular cultural tradition.

Out of necessity, especially in today's mobile world, it is also imperative to consider how diaspora, dislocation, and migration challenge notions of accessing and performing "pure" forms of culture, ethnicity, and identity, though our thinking and research often ignores these realities. Inherent in this is the problematic and taken-for-granted notion that culture (which is usually seen as elemental to identity) can remain free of influence from outside forces. In fact, literature on migration and identity often frames those who are not physically residing within culture-rich physical spaces as being between 'two cultures'. Further, these individuals may be researched in terms of assimilation and/or acculturation (vis-à-vis the receiving community), and the extent to which the culture of their ancestry is diminishing relative to that of 'mainstream' society (Back 1996; Sellers et al. 2007). In other words, the strictures of cultural absolutism suggests limited bounds-both physical and behavioralwithin which one can manifest authentic forms of cultural identity: a challenge to the reality of mobility, globalisation, and dislocation.

\section{Inventing Culture?}

In writing about the politics of identity that San communities in Namibia often negotiate, Sylvian (2003) describes a situation where non-San (in and outside of government) often hold the view that since many who claim San identity no longer live in traditional wayshunting and foraging for food versus working on farms or living in urban areas - the idea of the 'Bushman' is a fiction of Colonialism and capitalism. 'Modern Bushmen', therefore, are inventing or creating new identities as they go, and these constructions cannot be 'true' since they have left ancient ways of life behind. Of course, in the case of the San, rights to land and other resources if they are perceived to 
be authentically indigenous, are at stake. But, most importantly, their agency and autonomy in terms of living their identities in contemporary times based on the opportunities and constraints at their disposal, are also at risk. In some cases, 'traditional' communities are unavailable to the San because of colonial-era land grabs, intermarriage with non-San peoples, or the need to find paid work as a means of survival. The reality for those making such choices is that they are precluded from qualifying for official recognition since they no longer live in their 'traditional communities' where they practice 'traditional' culture.

In this specific case, and often, more broadly when indigenous identity is considered, culture is defined in limited ways. It is sometimes seen as some kind of emblem or practice associated with a group, as a worldview by which we make sense of our world (Mannheim 1929), or as Durkheim (1966) conceptualised culture: patterned ways of knowing and doing-so that culture acts as structure.

Of course, in the case of the San, Indigenous Australians, Maori, Native American, or any other indigenous or First Nation people, the notion of cultural identity becomes bound up in narratives of belonging to a place, an ancient time, and a static culture. Identity enactment is constrained by elements of essentialism fixity-narrowly defined standards of behaviors that are steeped in the 'ancient' and are never open to change. Nowhere in this conception are the realities of conquest and colonialism, alienation, violence, and all forms of degradation: mental, physical and cultural.

Bourdieu's (1990) conception of 'habitus' sees culture as performative, agentic, and emergent. A combination of artifacts, behaviors, and dispositions that emerge from social structures -habitus, by definition, cannot exist outside of history, experience, and individual 
dispositions. This form of culture is active and interactive. It incorporates and adopts that which operates outside of the individual, but it does not necessarily herald meaningful change to one's identity, intellect, or emotional adjustment.

If 'traditional' practices and cultural expressions of a particular (i.e. ancient) kind become insupportable, and others emerge in the fullness of time, are these new forms 'invented' or inauthentic? What happens to indigenous identity as it travels through modernity? At war are rigid, totalised, doctrinally based conceptions of what it means to be a real San/Indigene versus the fluidity and flux of performing identity that reflects the discursive elements of social reality and cultures that emerge as a result of time, place, and histories of conquest and oppression.

\section{Creolisation: A Cultural Form}

The term Creole emerged during the Colonial period to reference those offspring of Old World' individuals who were born and raised in New World societies. The word comes from the Latin verb creare 'to create.' By the 1600s in the Spanish and Portugese languages, forms of the word existed-criollo/crioulo-to mean those of mixed descent, or both black and European.

Like 'culture' the word went on to have many meanings, many of them laden with negative connotations. For example, Creole is often used in linguistics to mean a non-standard or broken form of a particular language that may be recognised today as a unique linguistic form-but none-the-less, one that had its roots in a previous mother tongue (Brathwaite 1971; Mintz 1971; Vaughan 2005). Another example comes from cultural theory. In tackling the identity dilemma of descendants of enslaved Africans and formally colonised 
peoples, cultural theorists of the last fifty years sought to escape the dialectic, racist boundaries inherent in categorising peoples (Stoddard and Cornwell 1999). Since racial mixing is a reality in most formally colonised populations, using terms like "hybrid" came into vogue when referencing these groups. Within the discourse of postcolonial and cultural studies, however, hybridity suggests some "pure" beginnings and the subsequent crossing of boundaries that then leads to a transgression. This transgression would then be called a "hybrid." Inherent in this conception is the dialectic that is at the heart of racewe are either one or the other, and hybrids represent yet a third entity that is neither. Hybridity therefore cannot exist outside of meanings of what constitutes "purity"-and by extension, the impure or hybrid form. Creole as an analytic framework, therefore, acts as an intellectual corrective to the notion of hybridity because the assumption of nativity is inherent in its meaning. It is about how cultural and institutional forms evolve in a particular place and time, and from a particular ethos: that of colonisation, a slave plantation economy and the power and race dynamics that was unique to that setting. Creolisation as a discourse, therefore, is a dynamic process of intercultural fusion-its parts leading to a particular whole in a specific context. One is very much native to a place (and, by extension, to a historical moment) even as one's roots may hail from a local or cultural context which is far removed. To simultaneously 'belong' and 'not belong' challenges biologistic and essentialist notions of any identity designation.

Some scholars of Caribbean culture-a major geographic seat of Creole culture-argue that Creolisation as a theory of cultural and identity must necessarily reside within Creole peoples (Black/European) in the New World, that its explanatory power is diluted outside of that context, and that its ability to 'travel' to other regions and people is hampered by its specificity (Mintz 1971). That 
view is not uniform. Glissant (1989), for example, a Martinician scholar and novelist, extends the concept outside of racial boundaries to people everywhere. Because no culture can be free of outside influence, the most important feature of what it means to be Creole is the reality of a complexity of cultural forms that have evolved historically. This is not about the loss of culture. Rather, the evolutionary process represents an "interactional and transactional" process that forges a contemporary identity form from the reality of colonisation, conquest, and the meeting and mixing of different cultural forms (Barnabe et al., 1990, 891). This thinking liberates Creolisation from its rootedness in meanings associated with "race" and allows me to focus on the concept as a means of highlighting interculturation or cultural transformation through mixing-a concept at the heart of contemporary emergent indigenous identities.

\section{Emergent Indigenous Identities}

Thus far I have made an argument for the necessity to move beyond arguments for a real or "pure" indigenous identity. This kind of thinking embodies an essentialism that relies on notions of purity and separateness. Indigenous people within any particular ethnic group cannot constitute a monolithic entity. Multiple contemporary realities predispose and shape myriad experiences, which in turn, lead to socially heterogeneous and dynamic ideas of the self. Research on identity formation supports this notion.

Early sociological research on the self led Mead (1912, 1925, 1934), a social psychologist who during the first decade of the twentieth century, wrote about identity in terms of the "I" and "Me." $\mathrm{He}$ conceptualised these as a dynamic grounded self-formation made up in part of how others define us and also what we create on the way to answering the question of "who am I?" Identities are formed in 
relation to the ways people inhabit roles, positions and cultural imaginaries that matter to them, e.g., a singer, a mother, an Aboriginal, a Maori.

We act out these identities in the course of coordinated social activity and everyday encounters with others. A Meadian identity is a sense of oneself as an actor in the social roles and positions defined by a specific, historically constituted set of social activities. In this configuration, identities are understood to be multiple, and while some may be longstanding and enduring, others may be disposable and fleeting. Some are ascribed: they come about as a result of how others see us. All, however, are dynamic entities-open to growth and change. There were two important points in Mead's conception: firstly, that the self was a complex, emergent phenomenon continually produced in and by individuals in their interactions with others and with the material world, and secondly, that the social position and roles, cultural symbols and other resources found in the material world, provided both opportunities and constraints for self-making. In other words, cultural genres and artifacts are the means through which we act out and/or represent identity, and even more importantly, identities themselves are part of more encompassing cultural constructions.

This last point involving the issue of culture is an important one. In today's world, many lay claim to "global" or diasporic identities as a means of claiming a political space where, I believe, we want to tell a story that constructs a reality of transcendence and contestation, and thereby lodge a protest against the stricture that culture and identity suggests, and that is so often inherent in racialised discourse. Yet, to do this may land one in the trap of glossing over the cultural, hierarchic, and hegemonic practices that are so important to 
understanding the "space" we occupy in a society, and ultimately the leverage we have to perform our identities.

The concept of an emergent indigenous identity honors this space. Inherent in the concept is the recognition of the fact that identities are comprised of multiple components including the social and the personal-or where we fit in the social order. I am going to call this positionality, and use it to mean the space we occupy at the intersection of structure (place in the social order) and agency (meaning making and practice). The concept involves the lived experience in which identification is performed as well as the subjective appraisal of one's worth and utility in particular settings.

This positionality is often manifested in narratives or disclaimers of belonging. These narratives reflect, I contend, the social and cultural milieu in which one operates and also the epistemological (knowledge) and ontological (being) contexts of one's life. So hierarchies and social positions are always shifting -an Indigene could be powerless in certain institutional contexts, but exert power in interaction with peers by belittling, or in another instance, holding a position of an elder statesperson. Both of these contexts position people differently and reflect the situated nature of claims and attributions and their production in complex and shifting locals. I want to note here (though I will not say more about it) the recognition of the complexity of positionality when one considers the interplay of the range of locations in relation to gender, ethnicity, national belonging, class and racialisation.

A dictionary definition might explain 'emergent' as a process of coming into being or becoming prominent. When coupled with the term identity and placed in the context of the preceding discussion, it emerges as an agentic and dynamic process that unfolds through 
social and cultural activities and relationships. An emergent identity is an evolving integration of the self and "other" (or what is outside the self) through participating in activities that give meaning to who we are. It becomes manifest in the context of personal, social and cultural influences.

Emergent identities accommodate interculturation: cultural transformation through mixing. There is often a critique of (loss of culture) or "deculturation" by the gatekeepers of "authentic" culture. There is nothing static or unchanging about indigenous cultures and therefore, indigenous identity. It, like every other culture, is fluid and must change and adapt over time. Can there be authentic culture? Moreover, to those who do not have the luxury of "authentic" modes of cultural expression, there really is no loss! Rather, it is accretion that occurs, or cultural enrichment. Of course, we must recognise that at the heart of this debate is the issue of (masked) power relations that raise critical questions about social location of those performing and reading the process of interculturation.

Emergent indigenous identities make room for those on the outside of the orthodoxy (or those, who by their very existence, are "Creole" per Bernabe et al.). They, too, are drawing on the complex cultural sources available to them. They are affirming their legitimacy through the production of intentionally mixed cultural forms. Some of these forms are deliberately created to express experiences and identity, and some have been imposed in that they have been passed down from generation to generation. In either case, those claiming indigenous identities do so in contemporary times using subjective symbols that announce their belonging to a particular community-one that is distinct from most "national" populations. 
Finally, emergent identities recognise the performative nature of identity. It is discursive as well as a social reality, and any performance's endurance or demise will depend on either feelings of satisfaction (and the subsequent decision to continue an action), or appraisals of diminishing utility (and a decision to cease acting in a particular way). This element of enactment does not entail fixity or essentialism; rather, it speaks to the complex appraisals of costs and benefits that are the motivational heart of identity performance. Most importantly, performing identity highlights agency—the ability to act deliberately and purposefully.

\section{Conclusion}

To identify as an indigenous person, according to Levi and Dean, is to utilise an "idiom of social belonging" to a people whose "histories, habitats, and lifeways distinguish them from dominant "national" populations" $(2006,8)$. Yet, to do so often locks one into a trap of monolithic, fossilised, and essentialised characteristics of identity performance. In fact, claiming indigeneity often demands the demise of all other identity markers or positions and leaves individuals in the position of defending their performance of a "real" or "pure" form of this identity status. In this essay I have tried to problematise this tendency and to delineate the concept of emergent indigenous identities as a corrective. That which is emergent is in the process of becoming-a state which connotes growth and change. Sociohistorical conditions, ideological variations, and the personal ecologies of people's lives impact identity construction and lead to a diversity of interpretations of what it means to be indigenous.

Creolisation, as an analytical tool, offers us a way to understand emergent indigenous identity, not as a biologically rigid or culturally essential entity, but as an agentic, interactional, and adaptive response 
to the questions, "Who am I?" and "What does it mean to be 'me' as an indigenous person?" Emergent identities reject the necessity to access 'authentic' culture since, by its very definition, it is never available in this space and time. Moreover, these dynamic selfproclamations embrace interculturation-the cultural transformations that come via mixing. Most importantly, emergent indigenous identities must reject the notion that the 'new' identities are 'deculturised' or lacking in authenticity since that luxury of the authentic is not currently available. This is in no way loss; it is, in fact, cultural enrichment.

\section{References}

Anathias, F. 'New Hybridities, Old Concepts: The Limits of Culture'. Ethnic and Racial Studies 24, no. 4 (2001): 619-641.

Ang, I. On Not Speaking Chinese: Living Between Asia and the West. New York: Routledge, 2001.

Ariss, R. 'Writing Lack: The Construction of an Aboriginal Discourse' In Past and Present: The Construction of Aboriginality, edited by J.R. Beckett, 131- 146. Canberra: Aboriginal Studies Press, 1988.

Back, L. New Ethnicities and Urban Culture. London: UCL Press, 1996.

Bernabe, J., P. Chamoiseau, and R. Confian 'In Praise of Creoleness' Callaloo, 13, no. 4 (1990): 886-909. Translated by M.B.T. Jhyarr from E'loge de la Creolite. Paris: Gallimard, 1989.

Bourdieu, P. The Logic of Practice. Oxford: Polity Press, 1990.

Brathwaite, E. The Development of Creole Society in Jamaica 17701820. Oxford: Clarendon Press, 1971.

Bruner, E M. and B. Kirshenblatt-Gimblett. 'Maasai on the Lawn: Tourist Realism in East Africa' Cultural Anthropology, 9, no. 4 (1994): 435-470. 
Conklin, B. 'Body Paint, Feathers, and VCR's: Aesthetics and Authenticity in Amazonian Activism', American Ethnologist 24, no. 4 (1997): 711-37.

Dean, B. and J. M. Levi. At the Risk of Being Heard. Ann Arbor: The University of Michigan Press, 2003.

Durkheim, E. The Rules of Sociological Method. New York: The Free Press, 1966.

Fiske, J. 'Boundary Crossings: Power and Marginilisation in the Formation of Canadian Aboriginal Women's Identities' Gender and Development 14, no. 2 (2006): 247-258.

Gilroy, P. Small Acts: Thoughts on the Politics of Black Cultures. London: Serpent Press, 1993.

Glissant, E. Caribbean Discourse: Selected Essays. Charlottesville: University of Virginia Press, 1989.

Goldie, T. Fear and Temptation: The Image of the Indigene in Canadian, Australian and New Zealand Literatures. Kingston: McGill-Queens University Press, 1989.

Hall, S. 'New Ethnicities.' Black Film, British Literature: ICA Documents 7, London: Institute of Contemporary Arts, 1989.

Manheim, K. Ideology and Utopia. London: Routledge, 1929.

Mintz, S. 'The Socio-historical Background to Pidginization and Creolization.' In Pidginization and Creolization of Languages, edited by Dell Hymes, 481-496. Cambridge: Cambridge University Press, 1971.

Paradis, Y. 'Beyond Black and White: Essentialism, Hybridity and Indigeneity.' Journal of Sociology 42, no. 4 (2009): 355-367.

Ravitz, J. (2009). 'New Jews' stake claim to faith and culture.' CNN, October 30, 2009. Accessed November 30, 2010, Accessed November 30 , 2009, http://www.cnn.com/2009/LIVING/10/28/new.and.emergent.je ws/index.html 
Sellers, S., F. C. Hiu Ha, and M. Harris. 'Theorizing heterogeneity: Social and Economic Well-Being of Native Blacks, AfroCaribbean and African immigrants in the US.' Research in Race and Ethnic Relations, 14, 287-305. JAI Press, 2007.

Stoddard, E. and G. Cornwell. 'Cosmopolitan or Mongrel? Creolite, Hybridity and 'Douglarisation' in Trinidad.' Cultural Studies 2, no. 3 (1999):331-353.

Sylvian, R. 'Class, Culture and Recognition: San Farm Workers and Indigenous Identities.' Anthropologica 45, no. 1 (2003): 111119.

Taylor, C. 'The Politics of Recognition.' In Multiculturalism: Examining the Politics of Recognition, edited by Amy Gutmann, 25-73. New Jersey: Princeton University Press, 1994.

Vaughn, M. Creating the Creole island: Slavery in Eighteenth-Century Mauritius. Durham: Duke University Press, 2005. 